\title{
Reseña de libro \\ Responsabilidad social corporativa en las empresas: El impacto de la comunicación en la salud y socialización en el ámbito laboral para combatir las enfermedades crónico degenerativas del personal.
}

Este libro es fruto de la colaboración de varias académicas entre las que se incluyen a Marie Leiner de la Cabada, Patricia Jiménez Terrazas, Josefa Melgar Bayardo y Ma. del Consuelo Medina García. El libro tiene el objetivo de realizar una descripción de la importancia de la responsabilidad social en el ámbito laboral destacando la importancia de la comunicación y la socialización para combatir las enfermedades crónico degenerativas del personal.

El documento describe cuales son las principales causas de las enfermedades crónico degenerativas, así como la evolución de estas enfermedades en los diferentes grupos de edades de las personas. Desde la perspectiva de la administración de empresas, un empleado enfermo carece del rendimiento y desempeño laboral a diferencia de un empleado saludable. Por ello, la importancia de que las empresas cuenten con empleados sanos. Los autores mencionan que quizá los administradores no sean médicos para brindar ayuda a los empleados. Sin embargo, si pueden convencer a los accionistas para ayudar con programas de prevención de enfermedades crónico degenerativas y con ello generar una mayor productividad debido a que la empresa contará con empleados saludables.

El libro está divido en seis capítulos, el primero referente de las enfermedades crónico degenerativas y como estas son una de las principales causas de mortalidad en la actualidad, desplazando a las enfermedades de tipo infeccioso. En el segundo apartado aborda como el estrés laboral tiene una relación con el desarrollo de enfermedades crónico degenerativas. La comunicación en la salud como una estrategia de la prevención y control de enfermedades crónico degenerativas es comentada en el tercer capítulo. El

1 Doctor en ciencias de la administración por la UNAM. Docente investigador en la Universidad Autónoma de Ciudad Juárez. Correo electrónico ulises.mendoza@uacj.mx 


\section{DOXA}

pISSN: 2395-8758

eISSN: en trámite

cuarto capítulo ofrece un panorama sobre los programas de bienestar físico y como esto contribuyen al bienestar de los empleados. En la sección cinco se muestra como se realiza una campaña de prevención y atención a la diabetes. En el último capito, el sexto, se desarrolló y midió la eficiencia y satisfacción de un folleto desarrollado como tebeo/comic que ayuda a la prevención de enfermedades, en este caso de la diabetes.

Las enfermedades crónico degenerativas se han convertido en la primer causa de mortalidad en el mundo. Los adultos mayores son principalmente vulnerables a contraer este tipo de enfermedades. La prevención, los tratamientos y el cuidado de estas enfermedades requieren costos, los cuales son absorbidos por los pacientes, la familia y el sector salud. En México del 2001 al 2006 se vio un incremento en el gasto del 61\% en aquellos pacientes que no estaban asegurados.

Se espera que para el 2050 en México la población de la tercera edad sea un $28 \%$ más que en la actualidad, debido a los cambios demográficos que se han presentado en el país. Esto provocara que la esta población adquiera y muera de enfermedades no infecciosas como es el caso de las enfermedades crónico degenerativas. En el Estado de Chihuahua durante el 2010 el 42\% de las muertes fueron causadas por enfermedades del sistema circulatorio, cáncer y enfermedades endócrinas. Por ello, las autoras sugieren que existan más programas preventivos.

Menciona también que algunas enfermedades crónico degenerativas tienen una relación estrecha con el estrés, como lo son la obesidad, diabetes, colesterol, hipertensión arterial y cáncer entre otras. En la actualidad en muchos trabajadores debido a su excesiva carga laboral y a los cambios organizacionales presentan altos niveles de estrés. El estrés laboral es un mecanismo de defensa ante los cambios inesperados y depende las características y procesos psicológicos de cada individuo. Por ello, es importante que las empresas estén monitoreando y tengan programas para evitar o controlar el estrés en sus empleados.

Con respecto a la prevención de este tipo de enfermedades la comunicación juega un rol importante. Debido a que con la prevención se evitan factores de riesgos y con ello la probabilidad de contraerlas se reduce drásticamente. La comunicación seria emitir un mensaje claro de prevención para que las personas cambien sus actitudes personales con relación a su salud, por 
pISSN: 2395-8758

eISSN: en trámite

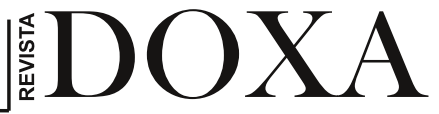

ejemplo, cuidar su peso y tener hábitos saludables.

Sin embargo, los beneficios son poco notables y no suceden de forma inmediata, además cuando una persona actúa de forma saludable, al inicio, todavía tiene probabilidades de enfermarse. Por ello, la acción de la prevención es quizá un acto de fe.

Una de las barreras en la comunicación, es que el comunicador es un proveedor de la salud y carece de habilidades comunicativas. El proveedor requiere simplificar la información para que el mensaje sea fácil de captar. Otro reto es que los receptores son diferentes, es decir, tienen diferente nivel social, cultural y económico. El receptor es un factor importante para que un mensaje sea efectivo.

En las empresas cada día los trabajadores enfrentan diversas tareas y problemas que ejercen presión en ellos, que aunados a los de la vida cotidiana aumentan el nivel de estrés, colesterol y el riesgo de un infarto. Por ello, las empresas cuentan con programas cuyo objetivo es promover el bienestar físico y mental. Los programas relacionados con la actividad física pueden ofrecer un gimnasio en el lugar de trabajo o bien proporcionar descuentos para que los empleados puedan acudir a uno y con estos ayudarlos a reducir sus niveles de estrés. El propósito de desarrollo de programas para el bienestar de los empleados por parte de las empresas es para reducir la inasistencia debido a que existen perdidas económicas por este motivo.

En el libro se hace un énfasis a las campañas de prevención y atención a las enfermedades crónico degenerativas considerando en especial el diseño y la construcción del mensaje para que tenga éxito. Se sugiere que estas campañas se benefician de usar en la producción el modelo de aprendizaje social. Diversos factores deben ser tomados en cuenta para un mensaje de salud pueda guiar la atención del receptor y sea efectivo, por ejemplo, los personajes, el color, el contenido, ser breve y conciso, la armonía y ser amigable en el mensaje. Todos los puntos anteriores son clave para que el mensaje logre transmitir el objetivo y cumpla su función de prevención.

Las técnicas en comunicación antes mencionadas fueron aplicadas en el desarrollo un folleto ilustrativo, que además fue evaluado para medir su eficacia y satisfacción. Los participantes de este estudio fueron estudiantes de la Universidad Autónoma de Ciudad Juárez y empleados de un banco local de ciudad Juárez Chihuahua, un total de 161 participantes, de los cuales 137 


\section{DOXA}

pISSN: $2395-8758$

eISSN: en trámite

participaron en el primera y segunda encuesta.

Los resultados con respecto a la eficacia mostraron que los participantes incrementaron su conocimiento con la lectura del folleto y que después de un tiempo determinado la información fue retenida por casi un mes. Los resultados se obtuvieron por una comparación de medias. En lo referente a la satisfacción del folleto los participantes se mostraron interesados con recibir más folletos con temas de salud.

El libro trae a discusión un importante elemento que pueden aprovechar las empresas en relación con su responsabilidad social hacia los empleados. Considerar la salud del trabajador como una prioridad que puede traer beneficios a la empresa y al trabajador que es importante considerar en el futuro.

\section{Referencias}

Leiner, M. Jiménez, P. Melgar, J. Medina, M. (2012). Responsabilidad social corporativa en las empresas: El impacto de la comunicación en la salud y socialización en el ámbito laboral para combatir las enfermedades crónico degenerativas del personal. México, Universidad Autónoma de Ciudad Juárez. 